\title{
A IMPORTÂNCIA DO ENSINO DE CIÊNCIAS NA PERCEPÇÃO DE ALUNOS DE ESCOLAS DA REDE PÚBLICA MUNICIPAL DE CRICIÚMA - SC
}

\section{THE IMPORTANCE OF TEACHING SCIENCE FROM STUDENTS' PERSPECTIVE IN PUBLIC SCHOOLS IN CRICIÚMA, SC - BRAZIL}

\author{
Aline Coêlho dos Santos ${ }^{1}$ \\ Cristini Feltrin Canever ${ }^{1}$ \\ Maristela Gonçalves Giassi ${ }^{2}$ \\ Paulo Rômulo de Oliveira Frota ${ }^{3}$
}

RESUMO: O ensino de Ciências nas escolas brasileiras, de modo geral, ainda acontece de forma tradicional e as pesquisas nessa área, costumeiramente, têm como foco o professor. Assim, este trabalho teve como objetivo identificar a percepção dos alunos sobre a importância do ensino de ciências em suas vidas. Trata-se de uma pesquisa qualitativa descritiva, com 216 alunos, do $6^{\underline{a}}$ ao $9^{\circ}$ ano, distribuídos em 7 escolas da rede pública municipal de Criciúmas/SC. Os resultados mostram que os alunos gostam de ciências e acham importante para sua vida, mas deixam claro que faltam aulas mais dinâmicas, interativas e práticas.

Palavras-chave: ensino de Ciências; ensino-aprendizagem; alunos; educação.

ABSTRACT: Science education in Brazilian schools generally still happens in a traditional manner and research in this area is usually focused on the teacher. This study aimed to identify the students' perception about the importance of science education in their lives. This descriptive, qualitative research was conducted with 216 students from 6th to 9th grade, in seven public schools in municipality of Criciúmas, SC. The results show that students enjoy science and feel that it is important in their lives, but make it clear that more dynamic, interactive, and practical classes are needed.

Keywords: Science education; teaching and learning; students; education.

\footnotetext{
1 Acadêmica do Curso de Ciências Biológicas - Licenciatura e Bolsista PIBIC. Universidade do Extremo Sul Catarinense. E-mails: aline.cds@live.com; cristinifc@hotmail.com

2 Doutora em Educação/UFSC e Professora titular da Universidade do Extremo Sul Catarinense. E-mail: mgi@unesc.net

3 Doutor em Educação/Ensino de Ciências-UFSC, Professor Titular da Universidade do Extremo Sul Catarinense e Coordenador do GP de Pesquisa Produção do Conhecimento no Paradigma Histórico-Cultural/UNESC.

E-mail: prf@unesc.net
} 


\section{INTRODUÇÃO}

$\mathrm{O}$ atual sistema de ensino do país vem enfrentando questionamentos que vão desde 0 processo de ensino aprendizagem, passando por sua estrutura física até a formação de professores. Percebe-se a todo instante na mídia, nas escolas e na sociedade uma insatisfação, seja dos alunos, dos pais ou dos professores. Se nos ativermos ao ensino de Ciências, foco de nossa pesquisa, trazemos as observações de Fourez (2003); este, quando fala numa crise nesta área de ensino, enfatiza que todos são atingidos por ela, "os alunos, os professores de ciências, os dirigentes da economia, os pais, os cidadãos [...]" (FOUREZ, 2003, p 110). A relevância dessa constatação se evidencia nos documentos propostos pela Academia Brasileira de Ciências quando destaca:

A necessidade imperiosa de melhorar o ensino básico no Brasil e, em particular, o ensino de ciências, [...] $\mathrm{O}$ ensino adequado de ciências estimula o raciocínio lógico e a curiosidade, ajuda a formar cidadãos mais aptos a enfrentar os desafios da sociedade contemporânea e fortalece a democracia, dando à população em geral melhores condições para participar dos debates cada vez mais sofisticados sobre temas científicos que afetam nosso cotidiano (Academia Brasileira de Ciências, 2008).

Contribuindo com essas informações, pesquisadores como Chassot (1990), Fourez (2003) e Maldanner (2007), observam que o ensino ainda se mantém de modo tradicional em nossas escolas, o que gera insatisfação por parte dos alunos e, em consequência, também dos professores e da sociedade, pois acabam sentindo os resultados dessa insatisfação.
Contudo, não existe em nossa região uma pesquisa que aponte como os estudantes percebem sua escola, seus professores e as disciplinas que têm que estudar diariamente, em outras palavras, qual o grau de satisfação dos alunos com o ensino que é ministrado nas escolas. A falta dessas informações leva também ao que se tem percebido em muitas escolas, nas quais os professores caminham com seu conteúdo sem que se deem conta de seu desempenho e da reciprocidade do aluno, especialmente no que tange ao processo de aprendizagem.

Por outro lado, o mundo científicotecnológico em que vivemos exige do cidadão conhecimentos mais apurados na área, e a disciplina de Ciências é a que mais oportuniza o enfrentamento dessa exigência. Cabe lembrar que é necessário estimular os alunos para esse campo do saber, pois o domínio do conhecimento científico é a alavanca para o desenvolvimento de um país. Além disso, possibilita também o conhecimento de sua própria vida e do mundo que o cerca.

Atentos a essa realidade, desenvolvemos esta pesquisa nas Escolas da Rede Pública Municipal de Criciúma/SC com alunos de quinta a oitava séries do Ensino Fundamental que teve por objetivo identificar a percepção dos alunos sobre a importância do Ensino de Ciências para as suas vidas. Os objetivos específicos foram: identificar as maiores dificuldades e facilidades apresentadas pelos alunos para o aprendizado de Ciências; identificar quais as metodologias que mais surtem efeito para o seu aprendizado; verificar quais os temas que mais gostam de estudar na área de ciências; e identificar o que mais os motiva a 
estudar Ciências.

Para alcançar os objetivos propostos, utilizamos uma metodologia de cunho qualitativo descritivo cujas questões norteadoras da pesquisa foram: Qual a percepção dos alunos sobre o Ensino de Ciências em Escolas da Rede Pública Municipal de Criciúma - SC? Qual a importância das aulas de ciências para a vida dos alunos? Quais as maiores dificuldades e facilidades que os alunos encontram para aprender ciências?

Fizeram parte da pesquisa 7 (sete) escolas da Rede Pública Municipal de Criciúma - SC, e para viabilizar a coleta dos dados, trabalhamos com as quatro séries de cada escola com uma amostra de 10 alunos de cada série e, em casos de escolas com mais de uma turma por série, pesquisamos em apenas uma turma de cada série. Para cada aluno foi aplicado um questionário com 13 questões, abertas e fechadas que contemplavam as informações necessárias para atender aos nossos objetivos.

\subsection{O Ensino de Ciências nas escolas}

Tem crescido nos últimos tempos as pesquisas visando a superar o modelo tradicional de ensino. Carvalho (2000), por exemplo, observa que em Biologia, atualmente, o ensino está reduzido à transmissão de conceitos prontos, e para ele, a escola tem outro papel. Para o autor, a escola deve dotar as pessoas de "condições teóricas e práticas para que elas utilizem, transformem e compreendam o mundo da forma mais responsável possível." Carvalho (2000, p. 4) (grifo do autor). Para o autor, a expansão da Ciência da Biologia trouxe a necessidade de se ensinar nas escolas o conhecimento produzido por ela, mas com o propósito de ser utilizado pelos alunos para lidar com aspectos de sua vida diária.

Historicamente, é possível perceber que o ensino de Ciências evoluiu de acordo com as circunstâncias e à época, acompanhando $\mathrm{o}$ desenvolvimento da sociedade, haja vista sua forte presença na vida do homem.

Autores como Krasilchik (1992), Bazzo; Pereira; Von Lisingen (2003) e Santos (2007) trabalhando com o conceito de CTS - Ciência Tecnologia e Sociedade, observam que o ensino de Ciências, passou por muitas mudanças até se chegar à elaboração do atual conceito que se tem de CTS. Segundo Krasilchik (1992), na década de 60, o ensino de Ciências passou por uma fase em que era apresentada como neutra e o importante eram os aspectos lógicos da aprendizagem e a qualidade dos cursos era definida pela quantidade de conteúdos conceituais transmitidos.

$\mathrm{Na}$ década de 70, novas mudanças foram estabelecidas e por conta da crise econômica mundial e dos problemas relacionados com 0 desenvolvimento tecnológico, surgiu no ensino de Ciências o movimento conhecido como "Ciência, Tecnologia e Sociedade" (CTS). Essa tendência no ensino leva à outra compreensão do mundo científico, pois contempla a estreita relação da ciência com a tecnologia e a sociedade, aspectos que não podem ser excluídos de um ensino que visa a formar cidadãos mais atuantes $e$ críticos, além de vivermos num momento entremeado de importantes problemas ambientais. 
Amorim (1997) entende que as relações entre a Ciência, Tecnologia e Sociedade caracterizam-se por uma nova postura nas escolas que implica tanto a escolha de temas que fujam de conteúdos tradicionais, devendo emergir de situações vinculadas à sociedade atual, marcadamente tecnológica, como na construção de metodologias de ensino que não se atenham à participação passiva dos alunos, mas que estimulem o debate, a postura crítica frente à participação da Ciência e da Tecnologia na Sociedade e a construção e efetivação de ações transformadoras dentro da sociedade.

Para Marques (2002), nesta dinâmica de interações, o professor deve livrar-se de conceitos aprendidos e repassados aos alunos. No seu entender o professor deve produzir com os alunos os conceitos que irão operar para entender as relações com que lidam. Para 0 autor, deve-se problematizar a realidade, criar situações para estimular o aluno. A sala de aula deve ser o lugar de falar, de ouvir, de modo que aconteça uma ampliação de conhecimentos dos envolvidos.

Segundo Freire (2005), a educação deveria ir muito além da repetição, constituindo-se em um instrumento de libertação, de superação das condições sociais vigentes. Para ele, "ninguém educa ninguém, como tampouco ninguém se educa a si mesmo: os homens se educam em comunhão, mediatizados pelo mundo" (FREIRE, 2005, p. 79). Essa mediatização ocorre por meio de uma educação problematizadora, de caráter reflexivo, de desvelamento da realidade, na qual o diálogo começaria a partir da reflexão das contradições básicas da situação existencial.
É nessa reflexão que o diálogo permite a educação para a prática da liberdade.

Também Delizoicov (2001) argumenta sobre a importância de problematizar os conhecimentos, visando a aguçar as contradições (FREIRE, 2005) e localizar as limitações desse conhecimento e ao mesmo tempo propiciar alternativas de apreensão do conhecimento científico. Para Delizoicov (2001), problematizar implica a escolha e formulação de um problema que seja significativo para o estudante, cuja solução exige um conhecimento que para ele seja inédito. É também um processo pelo qual o professor, "ao mesmo tempo em que apreende o conhecimento prévio dos alunos, promove a sua discussão em sala de aula, com a finalidade de localizar as possíveis contradições e limitações dos conhecimentos que vão sendo explicitados pelos estudantes, ou seja, questiona-os também." (DELIZOICOV, 2001, p. 133).

A Proposta Curricular de Santa Catarina PC/SC (1998), também faz referências ao trabalho exercido pelo professor. Para seus autores, este deve ter um "caráter pedagógico, no sentido da alfabetização científica" que pode ser realizada num processo pelo qual o aluno vai "decodificando a linguagem científica e se apropriando de elementos dessa linguagem, passando a utilizá-la como ferramenta de ação criativa no seu dia a dia." (SANTA CATARINA, 1998, p. 148). Para isso, de acordo com a PC/SC (1998), é necessário conhecer o que o aluno pensa, conhecer suas necessidades, anseios e sonhos.

Ensinar Ciências é fazer com que o aluno contribua para 0 seu próprio desenvolvimento, e que seja capaz de José dos Campos-SP, v. 17, n. 30, dez.2011. ISSN 2237-1753 
questionar, refletir e raciocinar. De acordo com os autores da PC/SC (1998, p.118) "Corresponde a uma elaboração de valores e não só de aquisições de informações. É preciso pensar para cada nível de ensino as maneiras de garantir esta construção de múltiplos componentes". O objetivo do ensino de Ciências é formar um indivíduo que saiba buscar o conhecimento, tendo competência e responsabilidade em suas ações.

Neste cenário entendemos que a pesquisa em pauta poderá contribuir para melhorar essa qualidade no ensino desejada por todos e nem sempre conseguida. $O$ processo de produção desse conhecimento implica pensar 0 ensino das ciências vinculado às peculiaridades da vida concreta das pessoas. Ou seja, ao dar um sentido ao processo educativo é necessário dar-se também um sentido àquilo que o aluno está ouvindo. Embora saibamos que isso nem sempre é uma tarefa simples, a escola precisa favorecer essa transição. Conforme Brasil (1999), o aluno deve se sentir "desafiado pelo jogo do conhecimento", deve adquirir $o$ "espírito de pesquisa e desenvolver a capacidade de raciocínio e autonomia" para poder transcender.

Apresentamos a seguir a análise e a discussão dos dados coletados na pesquisa.

\section{ANÁLISE E DISCUSSÃO DOS DADOS}

A partir das entrevistas obtivemos as informações que foram analisadas e discutidas conforme segue abaixo.

A primeira questão aplicada aos alunos dizia respeito ao gostar da disciplina de ciências. A pesquisa apontou que a maioria dos alunos, ou seja, 91,925\% dos entrevistados gostam de estudar Ciências, e afirmam que essa disciplina aborda assuntos muito interessantes, que contribuem de forma significativa em sua capacitação e desenvolvimento. Alguns ainda citam que gostam de ciências, pois a "professora é legal", o que deixa claro a influência que o docente tem sobre a disciplina. Grande parte dos alunos relacionou o gostar da disciplina com assuntos de seu maior interesse, sendo que os assuntos relacionados à saúde e corpo humano foram os mais citados, aparecendo de maneira bem expressiva em todas as escolas. Percebe-se que os alunos são capazes de se motivar em função de temas que lhes despertem interesse, que lhes são mais próximos e isso vem fortalecer a importância do ensino dentro de um contexto conhecido do aluno e compor uma aprendizagem mais significativa.

Nesse aspecto, Tapia e Montero (2003) observam que os professores notam a carência de interesse e motivação de seus alunos em aprender. Os autores relatam que, quando o aluno descobre o lado bom de cada matéria, ele irá desfrutar disso aprendendo; para os autores "o que o emociona e que o faz ter prazer é a experiência de aprender e descobrir, enfrentando os desafios que podem conduzi-lo a tais resultados" (TAPIA; MONTERO, 2003, p.107).

Para os autores, quando um aluno gosta de determinada disciplina ou conteúdo, ele apresenta-se mais motivado para os estudos e o seu esforço resulta em melhores resultados contribuindo para seu 
bom desempenho.

$\mathrm{Na}$ segunda questão, quanto à importância do ensino de ciências em suas vidas, também a maioria dos alunos entrevistados responderam que consideram importante, totalizando $97,85 \%$ das respostas obtidas. A justificativa girou em torno dos seguintes aspectos: "adquirir conhecimentos", "futuro profissional!" "cuidados com saúde e meio ambiente". Sendo que de um modo geral, 36,4\% acha importante para adquirir conhecimentos, $37,2 \%$ acha fundamental para cuidarmos de maneira correta do nosso meio ambiente e da nossa saúde e, por fim, 21,4\% acham necessário para um futuro profissional. Podemos observar mais detalhadamente na Fig. 1, as respostas obtidas pelos alunos de cada escola.

Nos gráficos, as escolas estão apresentadas por números que vão do 1 ao 7.

\section{"Por que o Ensino de Ciências é ímportante para nossa vida?"}

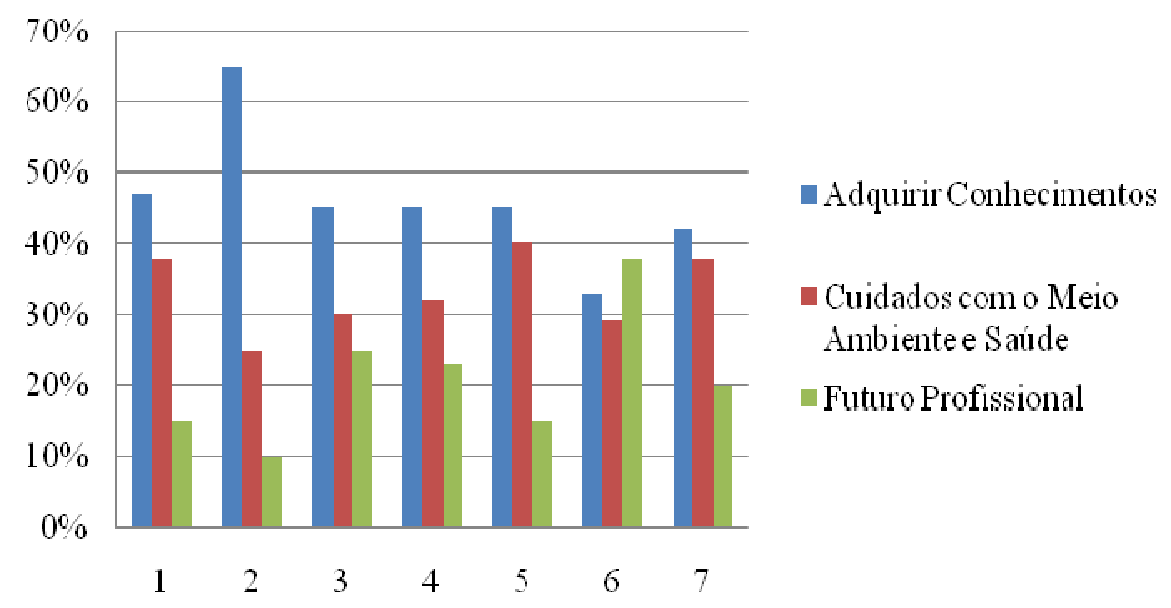

Fig. 1 - Respostas dos alunos.

Fonte: Dados coletados pelo entrevistador.

$\mathrm{Na}$ terceira questão, quanto aos conteúdos que despertam maior interesse nos alunos, pode-se notar que os relacionados ao Corpo Humano e Meio Ambiente apresentam maior destaque. $\mathrm{Na}$ Fig. 2, esses assuntos aparecem em porcentagens superiores em todas as escolas. Já, os demais assuntos têm frequências bem diferentes, apresentando grande variação.
Observa-se nessa fase dos alunos o grande interesse por seu próprio corpo e a saúde, depois vem o entorno mais imediato com os quais ele tem contato. Essa constatação vem confirmar o que Brasil (1999) indica quando destacam para a área das Ciências assuntos relacionados a Saúde e Meio Ambiente. Pesquisas em âmbito nacional realizadas com professores apresentam o mesmo resultado (SOUZA, 2002; TRINDADE, 2004; GIASSI, 2009) e 
com alunos (GIASSI; SIMÕES; GOULART; MARTINS, 2010). Nas pesquisas com os professores ficou claro que os temas que mais gostam de trabalhar são os voltados para o meio ambiente e para a saúde. Este é um campo que fica como sugestão para novas pesquisas, podendo-se investigar sobre fato de que os professores, ao gostarem mais de determinados conteúdos, saibam ministrá-los melhor, contagiando assim, sua turma com suas ideias.

Representação amostral dos conteúdos que surtem maior interesse nos alunos

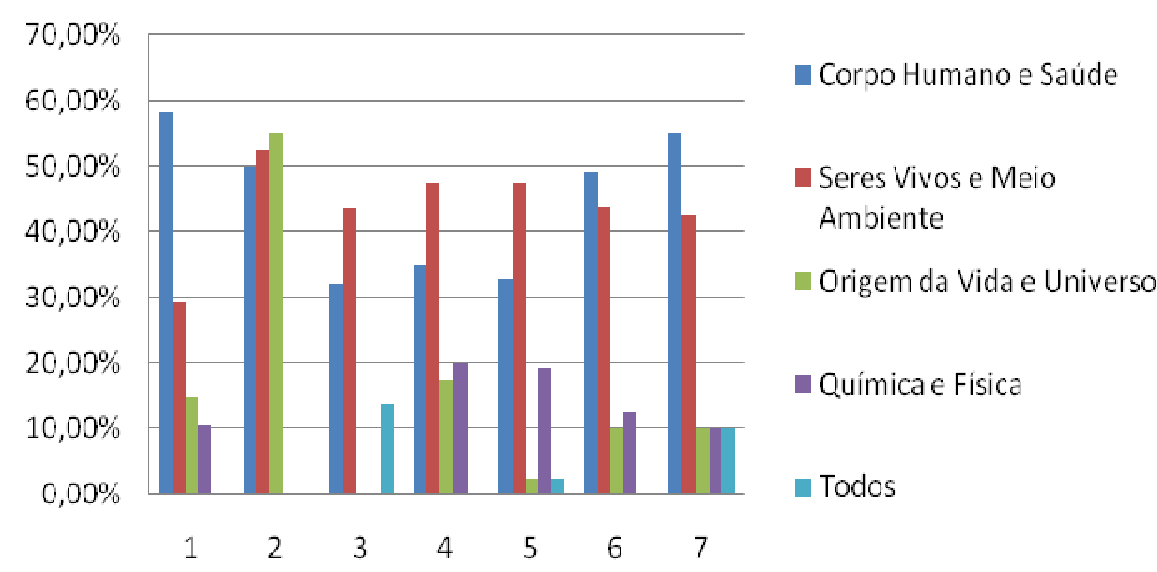

Fig. 2 - Resposta dos entrevistados referente aos assuntos que surtem maior interesse nos alunos.

Fonte: Dados coletados pelo entrevistador.

Dentre as metodologias de ensino relevância em todas as escolas, sendo que utilizadas pelos professores e que agradam outras formas de trabalho aparecem bem mais aos alunos, destaca-se o trabalho em abaixo, como podemos observar na Fig. 3. grupos. Percebe-se que este tem grande 
Representação gráfica dos métodos mais utilizados pelas professoras

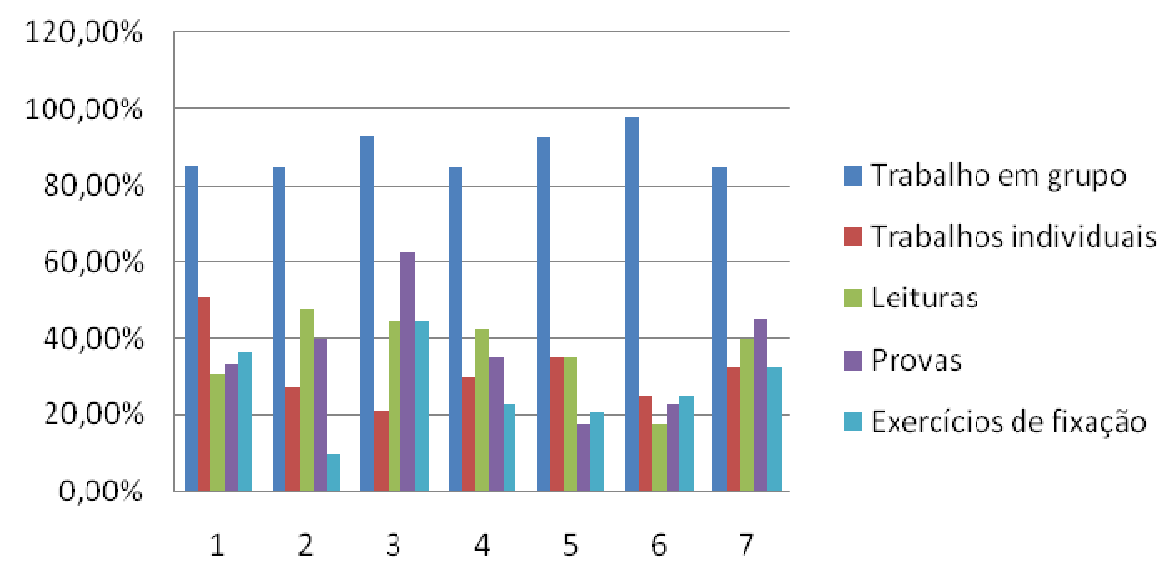

Fig. 3 - Métodos utilizados pelas professoras e que tem maior aceitação entre os alunos.

Fonte: Dados coletados pelo entrevistador.

Vygotsky (1989) observa que a maior parte da aprendizagem é construída a partir de relações sociais. Mediante as relações que trava no seu cotidiano, nas trocas de experiências, os alunos vão se apropriando de conhecimentos com os quais interagem, construindo seus próprios conceitos e/ou conhecimentos e, nesse sentido, os grupos são locais ideais.

Ainda no que tange a trabalhos em grupo, Flores e Gonzalez (2001), observam que a aprendizagem colaborativa é caracterizada pela presença de grupos de alunos que se responsabilizam pela interação que os levará a uma meta comum, sendo essa prática muito utilizada em nossas escolas.

Quanto aos recursos utilizados pelos professores em sala de aula, alguns têm maior aceitação pelos alunos do que outros, como podemos perceber na Fig. 4, que apresenta a média geral das respostas obtidas na pesquisa. 


\section{Recursos utilizados pelos professores que tem maior aceitação dos alunos.

$\begin{array}{ll}\text { Quadroe giz } & \text { Livro } \\ \text { Aulas de laboratório } & \text { Sala de informática } \\ \text { Experiências } & \text { Saída de campo }\end{array}$

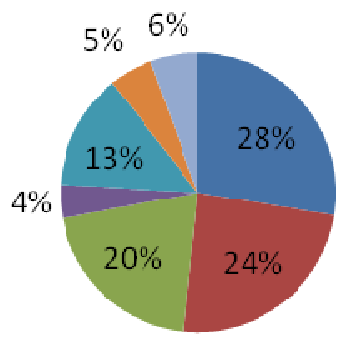

Fig. 4 - Recursos utilizados pelas professoras e que têm maior aceitação entre os alunos.

Fonte: Dados coletados pelo entrevistador.

Com base nas respostas dos alunos sobre os recursos mais utilizados em aula pelos professores, pode-se inferir que o "Quadro e Giz" são os mais utilizados, perfazendo um total de $89,3 \%$ das respostas. Observa-se ainda nas respostas dos alunos, que a maioria dos professores não realiza experiências ou práticas, nem saídas de estudos nas aulas de ciências, correspondendo a $62 \%$ das respostas dos entrevistados.

Neste aspecto, Carvalho e Gil-Pérez (1998), Schnetzler (2002) e Fourez (2003), explicam que os professores de Ciências desconhecem $o$ que as pesquisas e inovações didáticas vêm trazendo como fundamentais para o desempenho adequado de seu trabalho. Isso pode explicar essa ausência de atividades diferentes, criativas em sala de aula. E Chevalard (1991) chama a atenção para a complexidade de se transformar um objeto de saber produzido no âmbito dos cientistas em um objeto de ensino a ser tratado nas salas de aulas. Os autores apontam para o fato de que os cursos de formação de professores ainda deixam a desejar e assim os professores se ressentem na hora de trabalhar em sala de aula com metodologias diferenciadas que deem conta do que se espera da escola e de sua função.

Quanto às dificuldades apresentadas pelos alunos nas aulas de ciências, obtivemos resultados bastante positivos, pois $75 \%$ dos alunos responderam que não tinham problemas quanto às aulas de Ciências, e os poucos que falaram que apresentavam alguma dificuldade, justificaram que havia muita bagunça na sala de aula, ou seja, não relacionaram nem com o conteúdo e nem com o professor.

São justificativas que nos levam a refletir sobre a riqueza das salas de aula, pois mesmo diante da complexidade dessas 
relações, os alunos demonstram gostar das aulas mesmo com as deficiências destacadas nas respostas anteriores.

Quanto aos métodos e recursos utilizados pelos professores, questionamos se eles davam exemplos relacionados à vida do aluno, unindo a teoria com a realidade durante as explicações, $96,5 \%$ dos alunos afirmaram que sim.

Nesse sentido, os autores Freire (2005) e Delizoicov (2001), ao tratarem do processo de aprendizagem, afirmam que o professor(a) deve manter uma interação com seus alunos, a fim de tornar a aprendizagem significativa.

Para os autores, conhecer a realidade dos alunos e relacionar os conteúdos trabalhados em aula com essa realidade, com certeza torna a aprendizagem para os alunos mais significativa, faz com que os alunos tenham maior compreensão sobre os conteúdos.

$\mathrm{Na}$ questão referente aos recursos pedagógicos presentes nas escolas, todas possuíam alguns recursos tecnológicos como, por exemplo: data show, aparelhagem de vídeo e retroprojetor para ministrar aulas. $\mathrm{O}$ acervo desses materiais era pequeno, portanto era preciso reservar esses equipamentos com antecedência para poder utilizá-los. Apenas duas escolas apresentavam laboratório de ciências e algumas estavam em processo de reforma, tinham o espaço definido para laboratório, mas aguardavam a chegada dos materiais.

Para finalizar a pesquisa, pedimos que os alunos sugerissem algumas mudanças que, no seu ponto de vista, melhorariam as aulas de ciências, e então obtivemos as seguintes sugestões: Aulas mais dinâmicas, com saídas de campo, realização de experiências, utilização do laboratório de ciências e sala de vídeos.

Pediram ainda a realização de palestras com temas pertinentes como drogas e sexualidade, entre outros. Essas solicitações podem ser explicadas com as observações de autores como Marques (2002) e Freire (2005), quando chamam a atenção para a sala de aula, que muitas vezes não passa de um local onde o aluno apenas ouve passivamente, sem poder interagir, sendo apenas um espectador passivo. Esse resultado não é de todo desconhecido dos professores, no entanto ainda há um grande caminho a percorrer, muitos fatores interferem para que os professores aperfeiçoem sua prática pedagógica, objeto para outra pesquisa.

\section{CONSIDERAÇÕES FINAIS}

A pesquisa evidenciou alguns aspectos que fazem parte do dia a dia de nossas escolas, mas pouco divulgados para os professores.

A primeira constatação é a de que os alunos das escolas entrevistados demonstraram que gostam de ciências e acham importante para sua vida, mas deixam claro que faltam aulas mais dinâmicas, interativas, experimentais e práticas. Essas observações reforçam os resultados obtidos em pesquisas da mesma natureza realizadas sob o ponto de vista dos professores (SOUZA, 2002; TRINDADE, 2004; GIASSI, 2009) e dos alunos (GIASSI; SIMÕES; GOULART; MARTINS, 2010). Neste sentido, os autores destacam que o processo de ensino-aprendizagem se concretiza com maior eficiência se o aluno 
for um participante ativo e para isso o professor tem parcela importante, atuando como mediador desse conhecimento a fim de tornar a aprendizagem significativa.

Praia e Cachapuz (1994) observam que o professor tem um papel importante como mediador entre o conhecimento científico e o conhecimento do aluno, pelo que a sua grande preocupação não pode ser reduzida à simples aquisição de conceitos. Para Praia e Cachapuz (1994, p. 351), "os fatos não podem ser abordados duma forma descontextualizada, mas antes inseridos numa rede de razões, ou seja, discutido com os alunos de forma a desenvolver neles o pensamento crítico, as capacidades de fundamentação e de argumentação". Para isso, segundo os autores, a formação dos professores adquire importância vital.

O fato de os alunos gostarem das aulas de ciências pode ser um dos fatores que mantém vivo o desejo de ensinar, pois mesmo nas adversidades presentes nas escolas públicas no sistema de ensino de nosso país, sempre encontramos professores zelosos e também alunos, e aplicados, que, por sua vez, mantêm o ciclo de entusiasmo do processo ensino aprendizagem.

É possível inferir também que o simples fato da professora ser uma pessoa gentil que agrade ao aluno, já é motivo suficiente para este ir à escola satisfeito e gostar da matéria que estuda, como é o caso das crianças participantes desta pesquisa.

Assim, nossa investigação demonstrou que é possível realizar 0 que vem preconizado nos os Parâmetros Curriculares
Nacional para o Ensino Médio - Brasil (1999, p. 269), ou seja, que numa escola, mesmo em meio às adversidades poderá haver "mais alegria no aprendizado, entusiasmo nos afazeres, paixão nos desafios, cooperação entre os partícipes, ética nos procedimentos", e estaremos construindo a "cidadania em sua prática", formando valores humanos fundamentais que são centrais entre os objetivos da educação.

\section{REFERÊNCIAS}

ACADEMIA BRASILEIRA DE CIÊNCIAS. O Ensino de ciências e a educação básica: propostas para superar a crise. Rio de Janeiro: Academia Brasileira de Ciências, 2008. 56p.

AMORIM, A. C. R. O Ensino de Biologia e as relações entre Ciência / Tecnologia / Sociedade: $O$ que dizem os professores e 0 Currículo de Ensino Médio? VI Encontro "Perspectivas do Ensino de Biologia" Coletânea. Universidade de São Paulo Faculdade de Educação. 1997.

BAZZO, W. A.; LINSINGEN, I. V.; PEREIRA, L. T. do V. (Ed.). Introdução aos Estudos CTS (Ciência Tecnologia e Sociedade). Madrid: OEI, 2003 (Cadernos de IberoAmérica).

BRASIL, Ministério da Educação, Secretaria de Educação Média e Tecnologia. Parâmetros Curriculares Nacionais: Ensino Médio. Brasília: Ministério da Educação, 1999. 364 p.

CARVALHO, A. M. P. de; GIL-PÉREZ, D. Formação de professores de ciências: tendências e inovações. 3. ed. São Paulo: Cortez, 1998. 
CARVALHO, W. (org). Biologia: o professor e a arquitetura do currículo. São Paulo: Articulação Universidade/Escola Ltda, 2000.

CHASSOT, A. A Educação no Ensino de Química. ljuí: Unijuí, 1990.

CHEVALLARD, I. La Transposición didactica: Del saber sábio al saber enseñado. Buenos Aires: Aique Grupo Editor S. A., 1991.

DELIZOICOV, D. Problemas e Problematizações. In: PIETROCOLA, Mauricio (organizador) Ensino de Física: Conteúdo, metodologia e epistemologia numa concepção integradora. Florianópolis: UFSC, 2001. p 125-150.

FLORES, M.; GONZÁLEZ, S. Medios ambientes de aprendizaje colaborativo en educación a distancia: una experiencia en proceso. EGE, Escuela de Graduados en Educación. n. 5, p. 4-12, 2001.

FREIRE, P. Pedagogia do oprimido. São Paulo: Paz e Terra, 2005.

FREITAS, D. S.; PANIZ, C. M. Condições necessárias para o ensino na concepção de acadêmicos (as) de ciências biológicas da UFSM. RS, 2005. Disponível em:

www.ufsm.br/gpforma/1senafe/bibliocon/con dicoesnec.rtf. Acesso em: 04 jun. 2011.

FOUREZ, G. Crise no Ensino de Ciências? Investigações em Ensino de Ciências - v. 8, n. 2, p. 109-123, 2003.

GIASSI, M. G. A contextualização no ensino de biologia: um estudo com professores de escolas da Rede Pública Estadual do Município de Criciúma-SC. Tese de Doutorado em Educaçao Científica e Tecnologica. Universidade Federal de Santa
Catarina. Florianópolis - SC, 2009.

GIASSI, M. G. et al. Da teoria a prática: Ensinar e Aprender a Partir do Estágio Supervisionado de Biologia. (Artigo submetido ao $\mathrm{V}$ Congresso Internacional de Educação - UNIBAVE 2010.).

KRASILCHIK, M. Caminhos do Ensino de Ciências no Brasil. Em Aberto, Brasília, v. 11, n. 55, p. 3-8, jul./set. 1992.

MALDANER, O. A. Situações de estudo no ensino médio: nova compreensão de educação básica. In: NARDI, Roberto (organizador). A pesquisa em Ensino de Ciências no Brasil: Alguns recortes. São Paulo: Escrituras, 2007. p. 239-253.

MARQUES, M. O. Educação nas Ciências: interlocução e complementaridade. ljuí: Unijuí, 2002.

PRAIA, J.; CACHAPUZ, F. Un Análisis de Las Concepciones acerca de la Naturaleza del Conocimiento Cientifico de los Profesores Portugijese de la Enseñanza Secundaria. Enseñanza de las Ciencias, 1994 , v. 12 , n. 3, p. 350-354.

SANTA CATARINA, Secretaria de Estado da Educação e do Desporto. Proposta Curricular de Santa Catarina. Educação Infantil, Ensino Fundamental e Médio: Disciplinas Curriculares. Florianópolis: COGEM, 1998

SANTOS, W. L. P. dos. Contextualização no ensino de ciências Por meio de temas CTS em uma perspectiva Crítica. Ciência \& Ensino, v. 1, número especial, nov. 2007.

SCHNETZLER, R. P. Práticas de ensino nas ciências naturais: desafios atuais e contribuições de pesquisa. In: Didática e Práticas de Ensino; Interfaces com diferentes 
saberes e lugares formativos. ROSA, Dalva E. Gonçalves et al. (organizadores). Rio de Janeiro: DP\&A, 2002.

SOUZA, M. L. de. Ensinar a partir da Realidade do(a) aluno(a): Uma Investigação Sobre a Abordagem do Cotidiano no Ensino de Biologia. Dissertação em Educação - Centro de Educação e Ciências Humanas da Universidade Federal de São Carlos. São Carlos - SP. 2002.

TAPIA, J. A.; MONTERO, I. Orientação motivacional e estratégias motivadoras na aprendizagem escolar. In: COLL. C.; MARCHESI, A.; PALÁCIOS J. (orgs). Psicologia e Pedagogia. Nova Série).
Desenvolvimento psicológico e educação - 2: psicologia da educação escolar. Porto Alegre: Artes Médicas, 2003. p. 177-192.

TRINDADE, I. L. Interdisciplinaridade e Contextualização no "Novo Ensino Médio": conhecendo obstáculos e desafios no discurso dos professores de ciências. Dissertação (Mestrado) - Núcleo de Apoio ao Desenvolvimento Científico, Universidade Federal do Pará, 2004.

VYGOTSKY, L. S. A formação social da mente: o desenvolvimento dos processos psicológicos superiores. 3. ed. São Paulo: Martins Fontes, 1989. 168p. (Coleção 